\title{
Dorr on the language of ontology
}

\author{
Chris Daly ${ }^{1} \cdot$ David Liggins $^{1}$
}

The Author(s) 2016. This article is published with open access at Springerlink.com

\begin{abstract}
In the 'ordinary business of life', everyone makes claims about what there is. For instance, we say things like: 'There are some beautiful chairs in my favourite furniture shop'. Within the context of philosophical debate, some philosophers also make claims about what there is. For instance, some ontologists claim that there are chairs; other ontologists claim that there are no chairs. What is the relation between ontologists' philosophical claims about what there is and ordinary claims about what there is? According to Cian Dorr, ontologists' claims and denials of existence belong to 'a sort of professional jargon'. Dorr claims, for example, that (1) 'There are prime numbers between 20 and 30' can be used superficially or used fundamentally. Ordinary uses of (1) are superficial: we use the sentence to assert a boring, well-known truth. (Perhaps this truth is so well-known that only primary school teachers ever actually assert it.) But in the ontology room, (1) is used fundamentally, to assert that numbers are (as Dorr puts it) 'part of the ultimate furniture of reality': and this is a substantial metaphysical doctrine, not a boring truth. In this paper, we will show that none of Dorr's arguments for these claims succeeds.
\end{abstract}

Keywords Dorr $\cdot$ Metaontology $\cdot$ Charity

1. In the 'ordinary business of life', everyone makes claims about what there is. For instance, we say things like: 'There are some beautiful chairs in my favourite furniture shop'. Within the context of philosophical debate, some philosophers also

David Liggins

david.liggins@manchester.ac.uk

1 Philosophy, School of Social Sciences, University of Manchester, Oxford Road, Manchester M13 9PL, UK 
make claims about what there is. For instance, some ontologists claim that there are chairs; other ontologists claim that there are no chairs. What is the relation between ontologists' philosophical claims about what there is and ordinary claims about what there is?

A number of philosophers have recently claimed that there is a special 'language of ontology' and that sentences about what there is have different uses in different contexts. These philosophers include David Chalmers, Peter van Inwagen and Cian Dorr (Chalmers 2009; van Inwagen 2014, Introduction and Dorr 2005, 2008). Dorr's important work has not yet received the attention it deserves and the particular lines of argument which he offers raise a number of important issues of their own. For these reasons, in this paper we will concentrate evaluating Dorr's arguments.

Dorr $(2005,2008)$ offers an answer to the above fundamental metaontological question: the question of the relation between ontologists' philosophical claims about what there is and ordinary claims about what there is. According to Dorr, each of the sentences that (what he calls) foundational ontologists use to state their theories has at least two uses. Dorr claims, for example, that

(1) There are prime numbers between 20 and 30

can be used superficially or used fundamentally. Ordinary uses of (1) are superficial: we use the sentence to assert a boring, well-known truth. (Perhaps this truth is so well-known that only primary school teachers ever actually assert it.) Roughly speaking, an ordinary use of a sentence is a use of that sentence made outside of the context of the ontology seminar room. In the ontology room, however, (1) is used fundamentally, to assert that prime numbers are (as Dorr puts it) 'part of the ultimate furniture of reality' (2008: 34): and this is a substantial metaphysical doctrine, not a boring truth. Foundational ontologists' claims and denials of existence belongDorr tells us - to 'a sort of professional jargon' (2005: 249).

Similarly, Dorr maintains that (1)'s negation:

$(\sim 1)$ There are no prime numbers between 20 and 30

can be used either superficially - to assert the negation of the boring truth - or fundamentally - to assert the negation of the substantial metaphysical doctrine (itself a substantial metaphysical doctrine).

According to Dorr, the boring truth asserted in superficial uses of (1) is consistent with the substantial metaphysical doctrine asserted in fundamental uses of $(\sim 1)$. So one can deny that prime numbers are part of the ultimate furniture of reality without having to think that primary school teachers are feeding our children falsehoods.

One way to develop this idea would be to claim that the linguistic meanings of (1) and ( 1) change between the two contexts. But Dorr does not make this further claim. He is prepared to allow that that some pragmatic process accounts for the difference in what is asserted whilst the linguistic meaning remains unchanged (2005: 278 note 27; 2008: 34-5). With this clarification made, let us call Dorr's view contextualism.

Dorr is aware that contextualism threatens to render some philosophical debates obscure. If foundational ontologists' existential assertions are not to be interpreted in the ordinary fashion, then how should they be interpreted? This question prompts 
Dorr to put forward an elaborate account of 'what we disagree about when we disagree about ontology' (2005).

Contextualism is not obviously true. In fact, the burden of proof is on Dorr because of the prima facie implausibility of his view. If those he calls foundational ontologists use sentences such as (1) in two philosophically significant senses (superficial and foundational), it is odd that they themselves do not remark on these different uses. Dorr introduces the label 'foundational ontologists' for a certain subgroup of ontologists, while leaving it open which philosophers in fact belong to this sub-group. We suggest that many philosophers have argued against claims made by those outside the ontology room (and presented the same arguments against claims made in the ontology room). To mention some notable examples, Berkeley argued against Galileo and Boyle about the existence of matter, Hume argued against the Kirk about the existence of God, and Stebbing argued against Eddington about the existence of solid objects. These debates continue to the present day: ontologists such as William Lane Craig debate with contemporary scientists such as Lawrence Krauss, Peter Atkins and Lewis Wolpert about the existence of God.

Furthermore, we suggest that most leading contemporary ontologists are foundational ontologists. To give a short but hopefully representative survey, Lewis claims that there are other concrete worlds besides the actual world (Lewis 1986 chapter 1), van Inwagen claims that the only composite objects are living things (van Inwagen 1990), Jackson claims that everything that exists is physical (Jackson 2003), Sider denies that there are any composite objects (Sider 2011 chapter 13), and Schaffer claims that there is only one fundamental concrete particular (Schaffer 2010). Yet, if Dorr is to be believed, these ontologists' conclusions fail to be negations of their opponents' claims - and it is only now that we have discovered this. That is quite implausible. Still, Dorr marshals arguments in support of his view and they might dispel this prima facie implausibility. In this paper, we will scrutinize the arguments Dorr has offered and show that none of them succeeds.

Now, perhaps it is only sometimes that ontologists use 'there are'-sentence to express something other than what they would express in 'ordinary' contexts. In this case, however, some account would need to be given of (i) what are the occasions in which ontologists use 'there are'-sentences to express something other than what they would express by those sentences in 'ordinary' contexts and (ii) what it is about these occasions that trigger ontologists' use of 'there are'-sentences to express this different content. To bring this out, consider the above examples again. Do all, some or none of these examples involve a shift in what ontologists express by their use of 'there are'-sentences? If so, what features of a given example are responsible for this shift in content expressed by the use of the sentence and what is the mechanism by which this shift uniformly occurs whenever ontologists debate the issue in question? Lastly, as our examples show, ontologists debate with scientists about what there is. Does the same shift in content ever occur in the case of scientists' use of 'there are'-sentences or is the alleged phenomenon peculiar to the use of ontologists' use of 'there are'-sentences? If the latter is the case-and Dorr gives no indication to the contrary - the questions raised by (i) and (ii) become still more pressing. In summary: anyone who claims that only sometimes that ontologists use 
'there are'-sentence to express something other than what they would express in 'ordinary' contexts faces challenges that look difficult to overcome.

2. Dorr argues that his view is borne out by observing ontologists' behaviour:

Although many foundational ontologists are disposed to utter sentences which conflict with folk mereology, like 'there are no chairs', when they are engaged in ontological debates, the rest of the time they behave just like everyone else, uttering sentences like 'there are too many chairs in my office'. And even those foundational ontologists whose linguistic behaviour is less variable than this seem to take their colleagues' strange dispositions in their stride; they do not display the blank incomprehension which would be the natural response to people one took to be alternating between contradictory assertions. (2005: 249, footnote omitted)

We take it Dorr's argument is that if existential sentences did not exhibit the context-sensitivity he postulates, the ontologists mentioned at the start of the quotation would be contradicting themselves. Since they do not seem to be contradicting themselves, we should claim that the sentences they are uttering are context-sensitive.

Let us concede, for the sake of argument, that in every context the proposition expressed by 'There are too many chairs in my office' entails the proposition expressed in that context by 'There are chairs'. It still does not follow that contextualism is the best way to rescue chair-sceptics from contradiction.

An alternative explanation maintains that when these philosophers utter 'There are no chairs' in the context of ontological debate, they do not believe the proposition their utterance expresses within that context. Perhaps they think it is too early to say whether or not there are chairs; perhaps they think that, since ontologists have reached no consensus on the matter, we should suspend judgement (cf. Goldberg 2009). Such a philosopher will not believe the doctrines they are arguing for; in response to a charge of insincerity, they may claim that the best way to discuss them is to engage in philosophical debate as if they believed them. Far from being mired in contradiction, such a philosopher is merely giving a controversial theory a run for its money.

A second alternative explanation is that when the chair-sceptics utter 'There are too many chairs in my office' in an everyday context, they do not believe the proposition their utterance expresses (or is typically used to convey) within that context. They may draw back from believing it because they think it entails a refuted philosophical doctrine. In response to a charge of insincerity, they may claim that it would be impractical to behave otherwise: ordinary life would have to receive frequent interruption for long discussions about ontology (Dorr 2005: 255 even seems to note this). Indeed, one chairsceptic tells us that this is why he goes around uttering sentences he does not believe (Merricks 2003: 187-8; cf. Rosen and Dorr 2002:168-171, Braun and Sider 2007: 137). When faced with a chair-sceptic who appears to be inconsistent, we can rescue them by maintaining that one of these alternative explanations applies to them. ${ }^{1}$

\footnotetext{
1 In a discussion which complements our own, Korman (2015b: 57) independently suggests this explanation and adds another possibility (that in daily life the chair-sceptics 'lose sight of their philosophical convictions').
} 
Dorr's argument, then, has two failings. First, it is inconclusive. We need to be told why the available alternative accounts are inferior to contextualism and why it is the best potential explanation of ontologists' behaviour. Second, since ontologists do not accept his view, contextualism is not the actual explanation of ontologists' behaviour.

3. Dorr would resist this second charge. He also argues for contextualism on the ground that many ontologists are sympathetic to it. To back up this claim, he cites (2005: 249) a passage in which van Inwagen says that ordinary utterances of 'There are chairs' are literally true (van Inwagen 1990: 101) and compatible with his doctrine of the non-existence of chairs.

There are two problems with this line of thought. First of all, even ontologists who sound sympathetic to contextualism may not maintain this sympathy consistently. It is clear that van Inwagen would be happy to express his philosophy of chairs in the Loglish sentence ' $\exists x x$ is a chair' (cf. van Inwagen 1990: 30, where the 'Special Composition Question' is formulated in Loglish). Now in his paper 'Meta-ontology', van Inwagen claims that the quantifiers of predicate calculus should be introduced using 'only the resources of ordinary English' (1998: 240): in particular, van Inwagen claims that ' $\exists$ ' 'expresses the sense of "There is" in ordinary English' (1998: 240). We would therefore expect him to believe that the sentence 'There are chairs' is false in ordinary English. So van Inwagen's contexualism is at best equivocal; Dorr has not given us a single clear example of a thorough-going contextualist.

The second problem is that there are ontologists who deny contextualism. For instance, Rosen and Burgess explicitly reject contextualism with respect to sentences such as (1) (Rosen and Burgess 2005, p. 525). And since metaphysics textbooks never mention that ontological doctrines are formulated in technical jargon, we suggest that their authors reject contextualism too. For instance, Campbell (1976), Jubien (1997), Loux (2002), Carroll and Markosian (2010), and Tallant (2011) all deal with ontology at some length but none of them mentions contextualism or any similar doctrine, let alone endorses it. The only textbook we know of devoted to the subject of ontology does not endorse contextualism either: Effingham 2013. Effingham does discuss Carnap's view that ontological questions admit 'internal' and 'external' readings; while that view resembles contextualism, Effingham neither endorses it nor says that it is widely endorsed. So Effingham does not come close to endorsing contextualism.

It might be variously replied that maybe those authors have not thought much about the issue of contextualism, or that they do not want to distract their readers with linguistic considerations, or that they tend to eschew the practice of using bare quantifiers in the foundational way in favour of making heavy use of 'in the final analysis' and cognate phrases. We do not find these alternative suggestions promising. It is precisely part of the remit of a textbook covering ontology to expound and explain important views and distinctions in the field. It would reflect adversely on the competence of an author if he or she had not had not regarded contextualism as deserving consideration despite the fact that it did. Whereas we might expect such professional negligence to occur in a handful of cases, it strains credibility to suppose that most authors of textbooks that cover ontology are careless 
enough to leave out this point which (if true) is utterly vital to understanding what ontological debates are about. In similar fashion, where linguistic considerations are relevant to marking important views and distinctions in ontology, we would expect them to be observed in a textbook on the subject. If a textbook seeks to introduce us to a given debate, and yet it does not mention different formulations which other philosophers have given the issue, it is thereby deficient. And where textbook authors make play with talk of what obtains 'fundamentally,' 'in the final analysis' and the like, one would expect them to explain the significance of these terms and to explain how 'p' differs from 'fundamentally, p' and cognate sentences. In doing so, such authors would be going over precisely the ground which concerns contextualism, and so one would expect these authors to discuss contextualism there. Lastly, since ontologists differ over the relation between ordinary and philosophical existence-talk — as Dorr admits (2005: 249)—it follows that we cannot justify contextualism by appealing to ontologists' metaontological opinions.

4. Dorr (2008: 33) invites us to consider people who have never reflected on metaphysics. Wouldn't it be odd (Dorr asks) if they held beliefs which are incompatible with the doctrine that everything is a material object? We should not think they hold such beliefs, so we should not think they assert them. Many such people are happy to assert sentences like 'There are prime numbers.' Dorr concludes that we should interpret ordinary uses of 'There are numbers' differently to philosophical ones.

However, it is attractive to think that that many religious believers who have never reflected on metaphysics believe in a transcendent God (perhaps on the basis of their parents' testimony). Their belief entails that not everything is material. So we do not think that it is so odd to that some beliefs formed outside the philosophy room should have ontological implications.

Where does Dorr's argument go wrong? Dorr appears to assume that if one has never reflected on whether there are immaterial things, all one's beliefs will be compatible with the philosophical theory there are no such things; but we should not think we have such pre-theoretical neutrality. In general, failing to reflect on a question is no guarantee that one's beliefs will be consistent with every answer to it. That is because we can obtain a belief that entails that $p$ without reflecting on whether $p$ : indeed, we can form the belief that $p$ without reflecting on whether $p$. Folk physics provides examples. Many of our folk physical beliefs clash with serious physical theories (see O'Leary-Hawthorne and Michael 1996). In order to make a case for contextualism, Dorr needs to tell us why things are different with folk ontology.

5. Another of Dorr's motivations for contextualism concerns inferences such as:

a. There is a planet that is distinct from some planet; so

b. The number of planets is greater than one.

and

$\mathrm{a}^{\prime}$. The Earth is round; so

$b^{\prime}$. The Earth has the property of being round. 
Dorr says that, outside of philosophy we 'treat arguments such as these as trivially valid' (2008: 33). Now ontologists can use (b) to make a claim that is false if the metaphysical doctrine that there are numbers is false; and they can use $\left(b^{\prime}\right)$ to make a claim that is false if the metaphysical doctrine that there are properties is false. According to Dorr, it is clear that nothing in the meaning of (a) or ( $a^{\prime}$ ) could stop them being true if these doctrines were false. Dorr infers that these doctrines are not entailed by (a) or ( $\left.a^{\prime}\right)$, and concludes that, outside of philosophy, (b) and ( $\left.b^{\prime}\right)$ are generally used to convey something compatible with them (2008: 33-4). Thus (b) and $\left(b^{\prime}\right)$ each have two uses, as contextualism claims.

Dorr's claim that outside of philosophy we 'treat arguments such as these as trivially valid' bears further examination. First, what does Dorr have in mind by arguments 'such as these'? Dorr offers only a narrow selection of examples: he presents supposedly trivially valid arguments for the existence of properties and of numbers. (For a wider palette of examples of such arguments, see Schiffer 2003 chapter 2). Perhaps Dorr's claim enjoys whatever plausibility it has because of his judicious selection of examples. It may well be that most English-speaking nonphilosophers have no axe to grind about whether there are numbers or properties. For the most part they have not given the issue much thought and would not especially care either way on what the outcome is. (b) provides at least the information that (a) provides. And, although it provides the extra information that there are numbers, an English-speaking non-philosopher will not care about this surfeit. In particular, he or she would know that relaying this extra information would not cancel or distract from the information it was supplementing. Similar points hold with respect to $\left(a^{\prime}\right)$ and $\left(b^{\prime}\right)$. It would be understandable, then, why such a speaker would not feel any hesitancy in replacing (a) with (b) and ( $\left.a^{\prime}\right)$ with $\left(b^{\prime}\right)$. We return to this point below.

Second, we agree that people readily infer (b) from (a). But that does not show that (b) is entailed by (a). To give another example: we readily infer 'Alex has heard of Aristotle' from 'Alex is a philosopher', but we do not think that the premiss entails the conclusion: rather, the argument is an enthymeme. To make it valid, we need to add the extra premiss 'All philosophers have heard of Aristotle'. In just the same way, (b) is not entailed by (a) alone, but it is entailed by (a) and (c) together:

(c) If there is a planet that is distinct from some planet, then the number of planets is greater than one;

and $\left(b^{\prime}\right)$ only follows from $\left(a^{\prime}\right)$ once we add $\left(c^{\prime}\right)$ :

$\left(c^{\prime}\right)$ If the Earth is round then the Earth has the property of being round.

Thus the inferences Dorr discusses are not 'trivially valid'; they are not valid at all (if we have deductive or model-theoretic consequence in mind). Dorr argues that (b), and sentences like it, must have two uses, because there is one use on which the inference from (a) to (b) is valid, and another on which it is not. But he has failed to identify a use on which the inference is trivially valid.

Could Dorr save his argument by focusing on the inference from (a) and (c) to (b)? The idea would be that, since the validity of this inference varies with context, 
we should posit more than one use of (b). But this rescue would fail, because in every context the inference is an instance of modus ponens and therefore valid.

Perhaps we have misinterpreted Dorr. In the course of his argument, he says that (b) and ( $\left.b^{\prime}\right)$, as used by ontologists, 'certainly do not follow analytically' from (a) or $\left(a^{\prime}\right)$. Moreover, he says that, as used outside of philosophy, (b) and ( $b^{\prime}$ ) can easily be heard as mere 'stylistic variants' of (a) and ( $\left.\mathrm{a}^{\prime}\right)$, and claims that this 'can't be an outright mistake' (2008: 34). These sayings suggest that by 'valid' he means 'analytically valid' - that is, 'valid in virtue of the meanings of the terms involved' (see Shapiro 2005: 654-7). So interpreted, Dorr argues for contextualism on the ground that the inferences he mentions become analytically valid once we leave the ontology room.

We question whether either of the inferences is analytically valid. Take the 'number of planets' example. We agree with Dorr that nothing in the meaning of (a) could stop it being true if the doctrine that there are numbers is false. That is, if there are no numbers, it is analytically possible (i.e. consistent with the meaning of (a)) that (a) is true. Where we disagree with him, however, is that, as we see matters, the meaning of (b) stops it being true if the doctrine that there are numbers is false. That is, if there are no numbers, it is not analytically possible (i.e. consistent with the meaning of (b)) that (b) is true. It follows that the inference from (a) to (b) is not analytically valid. Corresponding remarks apply to the inference from $\left(a^{\prime}\right)$ to $\left(b^{\prime}\right)$.

Dorr has not shown that either of these inferences has an analytically valid reading. He has pointed out that, in non-philosophical contexts, we are readily disposed to infer (b) from (a), and $\left(b^{\prime}\right)$ from $\left(a^{\prime}\right)$ and that these inferences feel obviously valid. But that phenomena can be readily explained without supposing that there is any reading on which the inferences are analytically valid. Perhaps we confidently believe (c) and ( $\left.c^{\prime}\right)$ : if that is the case, it is no surprise that we are quick to make the inferences Dorr cites (see Rosen and Burgess 2005: 531 for a similar suggestion).

Is anything else involved in the relevant inferences being trivially valid? Dorr thinks that, for each of these inferences, our degree of confidence in the conclusion is just as high as our degree of belief in the premise set. Furthermore, each of us proceeds as if the rest of us are willing to make the inferences. We are willing to substitute sentences such as (a) and (b) for one another in attitude and speech reports.

But these facts about non-philosophers' behaviour can also be explained without supposing that the inference from (a) to (b) is analytically valid. Given that you believe that (c), you would be as confident that (b) as that (a). And given that you believe that others believe that (c), you would be confident about substituting (b) for (a) in reporting other people's attitudes and speech.

We can return to our earlier point about the information conveyed by (utterances of) (a) and (b), respectively. Here is an illustration of how common background belief shapes the information conveyed by different sentences. Suppose we share the assumption that my neighbour is an adult male. I might inform you of something else about him by saying, 'My neighbour is unmarried.' But I might just as well have said, 'My neighbour is a bachelor,' given that that sentence entails that he is unmarried. The same additional information would have been conveyed by each 
sentence. As Stalnaker puts it, 'If the asserted proposition were accepted, and added to the common background, the resulting situation would be the same as if the second assertion were accepted and added to the background' (Stalnaker 1999: 49).

Likewise, suppose non-philosophers share the assumption that there are numbers. One speaker might inform another by saying, 'There is a planet that is distinct from some planet'. But she might as well have said, 'The number of planets is greater than one,' given that that sentence entails that there is a planet distinct from some planet. Given the common background beliefs of the speaker and her audience, the increment of information conveyed by the two sentences is the same.

Dorr might reply by claiming that, in ordinary contexts, the inferences from (a) to (b) and from ( $\left.\mathrm{a}^{\prime}\right)$ to $\left(\mathrm{b}^{\prime}\right)$ are analytically valid, because (c) and $\left(\mathrm{c}^{\prime}\right)$ are analytic in those contexts. Let us concede that the analyticity of (c) and $\left(c^{\prime}\right)$ would suffice for the analytic validity of the arguments. Dorr still needs to give us some reason to believe that (c) and ( $\left.c^{\prime}\right)$ are analytic in the everyday context. And this cannot be provided simply by appeal to our inferential practices.

Perhaps Dorr would say that these sentences appear to be analytic in the everyday context, but intuitions of analyticity can be explained away. As Margolis and Laurence 2003 argue, there are good explanations available of why sentences seem to be analytic which do not vindicate the analyticity of these sentences. Perhaps we classify sentences as analytic because they resemble paradigm examples of analyticities. If so, then we need to establish that our intuitions track the right sort of resemblance. If Dorr wants to rely on the claim that (c) and (c') seem, in the everyday context, to be analytic, then he needs to reckon with the case made by Margolis and Laurence.

Moreover, the claim that (c) and (c') are analytic is implausible. Such conditionals are unlikely to be analytic, as Bennett 2009: 56-7 argues. In brief, Bennett maintains that such conditionals are ontologically ampliative-the consequent implies the existence of something that is not implied by the antecedent-and that ontologically ampliative conditionals are not plausibly taken to be true in virtue of meaning alone. To make good on his claim of analyticity, Dorr should give an independently motivated account of the everyday meanings of the terms these sentences contain which has the analyticity of (c) and ( $\left.c^{\prime}\right)$ as a consequence. Until one is provided, Dorr's position will lack plausibility. And Sider 2009: 387-391 provides an extended discussion which shows that it is very difficult to provide such an account.

Lastly, we have a positive argument to show that, as used outside of philosophy, (b) and ( $\left.b^{\prime}\right)$ are not mere 'stylistic variants' of (a) and (a'). Again, let's focus on the 'number of planets' example. We suggest the following principle: if sentences $p$ and $p^{\prime}$ are mere stylistic variants of each other, then, for any sentence $q,\ulcorner p$ and $q\urcorner$ is a mere stylistic variant of $\left\ulcorner p^{\prime}\right.$ and $\left.q\right\urcorner$. Now, suppose we conjoin each of (a) and (b) with the sentence 'there are no numbers'. Then we have:

$\left(a^{*}\right)$ There is a planet that is distinct from some planet and there are no numbers.

(b*) The number of planets is greater than one and there are no numbers. 
We conjecture that English-speaking non-philosophers would regard (a*) to be at least consistent. We further conjecture, however, that they would think that $\left(b^{*}\right)$ is inconsistent. But then $\left(\mathrm{a}^{*}\right)$ and $\left(\mathrm{b}^{*}\right)$ do not have the same content. Now, sentences which do not have the same content are not mere stylistic variants of one another. So $\left(a^{*}\right)$ and $\left(b^{*}\right)$ are not mere stylistic variants of one another. By the above principle, it further follows that neither are (a) and (b) mere stylistic variants of one another.

Dorr might grant that there is an interpretation on which $\left(\mathrm{a}^{*}\right)$ and $\left(\mathrm{b}^{*}\right)$ are merely stylistic variants, but claim both that the most natural interpretation of 'there are no numbers' is the fundamental one as opposed to the superficial one, and that this interpretation is also to be applied to sentences such as $\left(a^{*}\right)$ and $\left(b^{*}\right)$ which embed 'there are no numbers.' Let us grant that this is the most natural interpretation of $\left(a^{*}\right)$ and $\left(b^{*}\right)$. Nevertheless, it is not clear how it would block the argument. Even given this interpretation of 'there are no numbers', $\left(\mathrm{a}^{*}\right)$ and $\left(\mathrm{b}^{*}\right)$ are not merely stylistic variants of one another. We conjecture that English-speaking nonphilosophers who applied Dorr's preferred interpretation of 'there are no numbers' would still regard $\left(a^{*}\right)$ as consistent and $\left(b^{*}\right)$ as inconsistent.

Finally in this, let us consider another possible version of Dorr's argument (one which does not appear explicitly in Dorr's papers but was put to us by an anonymous referee). This version has the merit of avoiding the notion of analyticity. It runs as follows. Consider:

1. Two is between one and three.

2. There is a number between one and three.

3. There are numbers.

(2) seems to follow trivially from (1), and (3) seems to follow trivially from (2), and so we would expect it to seem that (3) follows trivially from (1). (Even if the relation of 'following trivially from' is not transitive in general, we would expect it to behave transitively in cases such as these, where the inferences in question are cognitively undemanding.) But (3) seems not to follow trivially from (1). What explains this striking phenomenon? To argue for contextualism, Dorr might maintain that the best explanation is that (2) has multiple readings (or uses). For if (2) has multiple readings, then the reading of (2) on which (3) seems to follow trivially might not be the same as the reading of (2) in which it seems to follow trivially from (1).

We are not persuaded by this argument, because we do not accept that the alleged phenomenon is genuine. To us it seems that (3) does follow trivially from (1): if two is between one and three, then there are numbers. A situation where two is between one and three but there are no such things as one, two, or three because there are no numbers is clearly impossible. So we do not think that Dorr can make his case by appealing to this alleged phenomenon to establish contextualism. ${ }^{2}$

\footnotetext{
2 Our arguments here are relevant to the work of Amie L. Thomasson, who advocates a deflationary view of ontology based on the triviality of inferences such as that from (a) to (b) and that from ( $\left.a^{\prime}\right)$ to $\left(b^{\prime}\right)$ (see Thomasson 2015). Thomasson's work merits fuller consideration than we can give here.
} 
6. Similar considerations to those given in the previous section also apply to a related argument for contextualism offered by Dorr (2008: 53 no. 2). Dorr asks us to consider the following inference:

(d) Either there are no planets, or there is a planet; therefore

(e) Either the number of planets is zero or the number of planets is at least one.

Dorr argues that since (d) is analytic, (e) (as ordinarily used) must also be analytic. But (e) implies that there are numbers, and, assertions of existence made within the ontology room cannot be true in virtue of meaning, as Kant and Hume argued in reply to Saint Anselm. Thus, as used by ontologists, it is not analytic. Dorr concludes that (e) has more than one use.

This argument brings out the fact that contextualism is a surprising view. We don't think that Kant and Hume would have been happy to say that their criticisms of the ontological argument succeed only within a particular context (the context of ontological inquiry); or that 'God exists' exhibits the context-sensitivity which Dorr claims. In any case, our response to the argument is simple. Let us accept, for the sake of argument, that (d) is analytic. In deriving the everyday analyticity of (e), Dorr must assume that the following principles — as ordinarily used - are analytic too:

If there are no planets, then the number of planets is zero.

If there is a planet, then the number of planets is at least one.

Pre-theoretically, these principles seem obviously true, but we have been given no reason to think that they are analytic truths. Until Dorr supplies a reason, his argument remains inconclusive.

7. Dorr has a further argument for contextualism which he calls 'the argument from charity'. The argument is designed to show that 'the sentences that comprise folk mereology express truths in ordinary English', where folk mereology is to be understood as 'the theory that comprises all the general claims about composition which we typically take for granted in this way' (2005: 247). This argument of Dorr's is interesting because it draws upon quite a different set of considerations to his previous arguments. Despite Dorr's name for the argument, it is not clear that considerations of charity figure in it. Furthermore, Dorr disowns the view that the principle of charity suffices to establish the above conclusion (Dorr 2005: 278, note 24). This argument of Dorr's is also more restricted in scope than his other arguments. It bears upon mereology and the existence of composite things, but not upon other issues in ontology, such as the existence of numbers or properties.

At this point we should note that the interpretation of Dorr's paper is not entirely straightforward. It is possible to read this section of his paper not as arguing for contextualism but as presupposing it. We will stay neutral on this exegetical question, although for simplicity we will write as if the argument we discuss is definitely Dorr's. The argument we will discuss is at any rate suggested by Dorr's paper, and it matters whether it is successful. We will now set out the argument and pinpoint where it goes wrong.

The argument draws upon a thought experiment (Dorr 2005: 234-5). Suppose various tribes each speak a language which has the same syntax as English. Suppose 
also, however, that the speakers give different answers to the Special Composition Question. This is the question: Under what circumstances do several things compose one thing? (cf. van Inwagen 1990: 21-32). Dorr discusses several views about what should be said were the tribes to learn of each other's linguistic behaviour. One of these views is conciliatory. This view has two components: (1) a thesis about the truth-value of the answers which speakers of a language give to the Special Composition Question, and (2) a principle about the individuation of languages. The thesis about the truth-value of answers given to the Special Composition Question is, in Dorr's words, that 'In fact, the sentence expressing each tribe's characteristic answer to the Special Composition Question was a true sentence of that tribe's language' (Dorr 2005: 235). This thesis tells us that the different tribes speak different languages and this in turn implies a principle about the individuation of languages. The principle appears to be that languages are identical only if they have the same syntax and speakers of those languages offer the same answer to the Special Composition Question. At any rate, whatever the principle at work is, it specifies that tribes giving different answers to the Special Composition Question are tribes who speak different languages.

How does this thought experiment bear upon our own folk mereology? Dorr presents the following argument:

Folk mereology plays the same general sort of role for the community of ordinary English-speakers that each tribe's central dogmas play for that tribe. But the thought experiment of the tribes shows us that any sentences which play that sort of role in a community will express truths in that community's language. Hence, the sentences that comprise folk mereology express truths in ordinary English. (Dorr 2005: 247)

When the tribes are presented with the Special Composition Question, they are disposed to give certain answers. In the case of English speakers, the dispositions are more subtle, but those dispositions are similar enough to the tribes that if Dorr's conciliatory view about the tribes is correct, an analogous view applies to English speakers. By folk mereology playing 'the same general sort of role' for us as each tribe's central dogmas play for that tribe, we take Dorr to mean that we treat folk mereology as if it were 'completely obvious and unproblematic.' Given this, and the above principle about the individuation of languages, folk mereology is a partial determinant of which languages English is identical with. A language is identical with English only if speakers of that language give the same answer to the Special Composition Question as English speakers do.

Dorr stipulates that languages are identical only if speakers of those languages give the same answer to the Special Composition Question. There are reasons to doubt whether someone is a speaker of a given natural language only if they (at least implicitly) endorse certain theoretical principles (cf. Williamson $2007 \mathrm{ch}$. 3). But let us waive this consideration and make our main objection, which is to take issue with the second premise of Dorr's argument. We deny that his thought experiment provides reason to believe what he claims it does. Specifically, it does not show that the sentences which provide a given language's answer to the Special Composition Question express truths in that language. The thought experiment did report a certain view-a conciliatory view-which made precisely that claim. This is component (2) 
of the conciliatory view noted above. But the thought experiment provides no support for that claim. The thought experiment merely reports the conciliatory view as one view among others which some of the tribespeople take after they have learnt of the other tribes' linguistic behaviour. It does not provide an argument for the conciliatory view. Moreover, the two components of the conciliatory view are logically independent of each other. So even if (1) is accepted, it would be consistent to reject (2) But unless (2) is justified, the conciliatory view is unjustified. It follows that the thought experiment fails to show that any sentences which play the same role in a community as the tribes' dogmas will express truths in that community's language. It further follows that Dorr's conclusion that the sentences that comprise folk mereology express truths in ordinary English has not been established.

In presenting his thought experiment, Dorr says that he will first consider how proponents of the conciliatory view should interpret the languages of the different tribes-i.e., the language of the universalists, in which people say, 'For any two things, there is something they compose'; the language of the nihilists, in which people say 'Two or more things never compose something'; and the language of the organicists, in which people say 'Two or more things compose something only if that thing has a life'. He says that he will then consider what the proponents of these views should say about the debate over the Special Composition Question. In other words, as Dorr sets matters up, his whole paper is about the implications of the conciliatory view (Dorr 2005: 235-236). So the conclusions which Dorr then reaches (Dorr 2005: 247) are best interpreted as conditional:

If the conciliatory view is true then 'the thought experiment of the tribes shows us that any sentence which that sort of role in a community will express truths in that community's language'

and so

If the conciliatory view is true then folk mereology is true.

The chief problem with these conclusions, however, is that they fall markedly short. Dorr may have defended the conciliatory view from the objection that it cannot supply a semantics for all the tribes' languages. But he has not argued for the conciliatory view itself, and that view is far from obvious. Accordingly, if it is conceded that Dorr has established the above conditionals, he has not established the truth of folk mereology.

8. We have shown that Dorr's arguments for contextualism are at best inconclusive, and that the prospects for repairing them do not look rosy. For all Dorr has shown, the sentences ontologists use to state their theories convey the same claims in the ontology room as they do in ordinary contexts. It follows that Dorr's project of clarifying ontologists' jargon lacks a good motivation. If we have no reason to believe contextualism, and given that no reason has been given to believe the negation of contextualism, then we have no need for an account of 'what we disagree about when we disagree about ontology'.

We see no reason to doubt that when Dorr uses an ontological sentence in the ontology room, he intends to assert something other than the claim the sentence is 
used to assert in ordinary contexts. Furthermore, let us assume that associated with each of the sentences ontologists use to state their theories, there are two different claims: the claim the sentence is ordinarily used to assert, and the claim Dorr intends to assert when he uses the sentence in the ontology room. We have two concluding comments on the implications of this assumption.

First, it implies a significant danger of confusion and miscommunication. Dorr and those engaging in ontological debates with him would be well advised to make it perfectly clear which claim is under discussion. In particular, Dorr runs the risk of being misinterpreted as making the ordinary claim. It was wise of him to spend part of his 'There are no abstract objects' clarifying what he means by that phrase (Dorr 2008: 33-36). Before we can evaluate an argument, we must be sure what it is intended to show. Korman (2015a, b, chapter 6) argues that the usual arguments against the existence of composite objects fail if their conclusion is read in Dorr's way; his argument generalizes to other debates in ontology.

Second, it is unlikely that the presence of a single ontologist who puts the language of ontology to an idiosyncratic use will have any influence on the meaning of that language. To put it crudely, someone can misuse a sentence without making it ambiguous. However, it is plausible that if Dorr's communicative intentions were shared by a large group of ontologists, this would influence the meaning of ontological language, in such a way that (1), and similar sentences, would each have two different readings in the context of the ontology room. Then a view similar to Dorr's contextualism would be true. And if Dorr's communicative intentions became shared by every ontologist, Dorr's contextualism would then become true.

Acknowledgments Thanks to Cian Dorr, anonymous referees, and an audience at the Joint Session in Dublin, 2010, for valuable discussion. We gratefully acknowledge a grant from the Arts and Humanities Research Council.

Open Access This article is distributed under the terms of the Creative Commons Attribution 4.0 International License (http://creativecommons.org/licenses/by/4.0/), which permits unrestricted use, distribution, and reproduction in any medium, provided you give appropriate credit to the original author(s) and the source, provide a link to the Creative Commons license, and indicate if changes were made.

\section{References}

Bennett, K. (2009). Composition, colocation, and metaontology. In D. Chalmers, D. Manley, \& R. Wasserman (Eds.), Metametaphysics: New essays on the foundations of ontology (pp. 38-76). Oxford: Oxford University Press.

Braun, D., \& Sider, T. (2007). Vague, so untrue. Noûs, 41, 133-156.

Campbell, K. (1976). Metaphysics: An introduction. Encino, California: Dickenson Publishing.

Carroll, J. W., \& Markosian, N. (2010). An introduction to metaphysics. Cambridge: Cambridge University Press.

Chalmers, D. (2009). Ontological anti-realism. In D. Chalmers, D. Manley, \& R. Wasserman (Eds.), Metametaphysics: New essays on the foundations of ontology (pp. 77-129). Oxford: Oxford University Press.

Dorr, C. (2005). What we disagree about when we disagree about ontology. In M. E. Kalderon (Ed.), Fictionalism in metaphysics (pp. 234-286). Oxford: Clarendon Press. 
Dorr, C. (2008). There are no abstract objects. In T. Sider, J. Hawthorne, \& D. Zimmerman (Eds.), Contemporary debates in metaphysics (pp. 32-63). Malden, MA: Blackwell.

Effingham, N. (2013). An introduction to ontology. Cambridge: Polity.

Goldberg, S. C. (2009). Reliabilism in philosophy. Philosophical Studies, 142, 105-117.

Jackson, F. (2003). Mind and illusion. In A. O’Hear (Ed.), Minds and persons (pp. 251-271). Cambridge: Cambridge University Press.

Jubien, M. (1997). Contemporary metaphysics: An introduction. Oxford: Blackwell.

Korman, D. Z. (2015a). Fundamental quantification and the language of the ontology room. Noûs, 49, 298-321.

Korman, D. Z. (2015b). Objects: Nothing out of the ordinary. Oxford: Oxford University Press.

Lewis, D. (1986). On the plurality of worlds. Oxford: Blackwell.

Loux, M. J. (2002). Metaphysics: A contemporary introduction (2nd ed.). London: Routledge.

Margolis, E., \& Laurence, S. (2003). Should we trust our intuitions? Deflationary accounts of the analytic data. Proceedings of the Aristotelian Society, 103, 299-323.

Merricks, T. (2003). Objects and persons. Oxford: Clarendon Press.

O'Leary-Hawthorne, J., \& Michael, M. (1996). Compatibilist semantics in metaphysics: A case study. Australasian Journal of Philosophy, 74, 117-134.

Rosen, G., \& Burgess, J. (2005). Nominalism reconsidered. In S. Shapiro (Ed.), The Oxford handbook of philosophy of mathematics and logic (pp. 515-535). New York: Oxford University Press.

Rosen, G., \& Dorr, C. (2002). Composition as a fiction. In R. M. Gale (Ed.), The Blackwell guide to metaphysics (pp. 151-174). Oxford: Blackwell.

Schaffer, J. (2010). Monism: The priority of the whole. Philosophical Review, 119, 31-76.

Schiffer, S. (2003). The things we mean. Oxford: Oxford University Press.

Shapiro, S. (2005). Logical consequence, proof and model theory. In S. Shapiro (Ed.), Oxford handbook of the philosophy of mathematics and logic (pp. 651-670). New York: Oxford University Press.

Sider, T. (2009). Ontological realism. In D. Chalmers, D. Manley, \& R. Wasserman (Eds.), Metametaphysics (pp. 384-423). Oxford: Oxford University Press.

Sider, T. (2011). Writing the book of the world. Oxford: Oxford University Press.

Stalnaker, R. C. (1999). Pragmatic presuppositions. In his Context and content. Oxford: Oxford University Press, pp. 47-62.

Tallant, J. (2011). Metaphysics: An introduction. London: Continuum.

Thomasson, A. L. (2015). Ontology made easy. Oxford: Oxford University Press.

Van Inwagen, P. (1990). Material beings. Ithaca, London: Cornell University Press.

Van Inwagen, P. (1998). Meta-ontology. Erkenntnis, 48, 233-250.

Van Inwagen, P. (2014). Existence: Essays in ontology. Oxford: Oxford University Press.

Williamson, T. (2007). The philosophy of philosophy. Oxford: Blackwell. 